\title{
A Gestalt-Terapia em Tempos de Incerteza: A Potência do Não-Saber
}

\section{Gestalt-Therapy in Times of Uncertainty: The Power of Not- Knowing}

\section{La Terapia Gestalt en Tiempos de Incertidumbre: El Potencia de No Saber}

\author{
Luciana Bicalho Cavanellas* \\ Fundação Oswaldo Cruz - Fiocruz, Rio de Janeiro, Rio de Janeiro, Brasil
}

Ronaldo Miranda Barbosa**

São José dos Campos, São Paulo, Brasil

\begin{abstract}
RESUMO
Em tempos de incerteza, temos vivenciado a ineficiência do acúmulo de conhecimento técnico-científico na criação de um mundo mais satisfatório e equânime. As injustiças, as violências e os adoecimentos têm sido portavozes da crise humanitária que atravessamos, onde a vida tem se revelado tentativa de sobrevivência para uma maioria de pessoas, nos mais diferentes lugares. Diante da hegemonia de um tipo de saber dominante, que visa previsibilidade e controle, experiências de alteridade tendem a ser suprimidas e desqualificadas. A Gestalt-Terapia, nascida em berço existencial-fenomenológico, nos resgata a importância de um olhar que vai ao encontro do outro com abertura e coragem, acolhendo a diversidade e valorizando a força das experiências vividas. O cuidado se revela como atitude necessária de inquietação e desvelo, favorecendo a capacidade de confiar na gratuidade e na beleza dos encontros como fonte de aprendizado, experiência e conhecimento. O não-saber a priori acaba por revelar-se fonte potente de descoberta e criação de novas realidades.
\end{abstract}

Palavras-chave: gestalt-terapia, conhecimento, alteridade, cuidado.

\begin{abstract}
In times of uncertainty, we have experienced the inefficiency of the accumulation of technical-scientific knowledge in the creation of a more satisfactory and equitable world. Injustices, violence and illness have been spokespersons for the humanitarian crisis we are going through, where life has proved to be an attempt at survival for a vast majority of people, in the most different places. Faced with the hegemony of a dominant type of knowledge, which aims at predictability and control, experiences of otherness tend to be suppressed and disqualified. Gestalt-Therapy, born in an existential-phenomenological cradle, rescues us from the importance of a look that meets the other with openness and courage, welcoming diversity and valuing the strength of lived experiences. Care is revealed as a necessary attitude of restlessness and concern, favoring the ability to trust
\end{abstract}


in the gratuitousness and beauty of encounters as a source of learning, experience and knowledge. Not knowing a priori turns out to be a powerful source of discovery and creation of new realities.

Keywords: gestalt-therapy, knowledge, alterity, care.

\section{RESUMEN}

En tiempos de incertidumbre, hemos experimentado la ineficiencia de la acumulación de conocimientos técnico-científicos en la creación de un mundo más satisfactorio y equitativo. Las injusticias, la violencia y la enfermedad han sido los portavoces de la crisis humanitaria por la que estamos pasando, donde la vida se ha revelado ser un intento de supervivencia para una gran mayoría de personas, en los más diversos lugares. Frente a la hegemonía de un tipo de conocimiento dominante, que busca la previsibilidad y el control, las experiencias de alteridad tienden a ser suprimidas y descalificadas. La Terapia Gestalt, nacida en una cuna existencial-fenomenológica, nos rescata de la importancia de una mirada que encuentra al otro con apertura y coraje, acogiendo la diversidad y valorando la fuerza de las experiencias vividas. El cuidado se revela como una actitud necesaria de inquietud y preocupación, favoreciendo la capacidad de confiar en la gratuidad y belleza de los encuentros como fuente de aprendizaje, experiencia y conocimiento. El no saber a priori resulta ser una poderosa fuente de descubrimiento y creación de nuevas realidades.

Palabras clave: terapia gestalt, conocimiento, alteridad, cuidado.

Este artigo pretende afirmar a Gestalt-Terapia como uma abordagem possível e potente na tentativa de ver e viver um mundo que se descortina cismado, cindido, conflitante entre disputas de poder/saber, entre verdades decadentes e "falsas" verdades ascendentes, em um campo minado de notícias e acontecimentos.

Viver em nossa época tem significado, para muitos, sobreviver, porque apesar do acúmulo de conhecimento e patamar tecnológico que alcançamos, a vida não cansa de escancarar nossa ignorância em relação ao outro, aos diversos outros e a nós mesmos. Não admitimos o que não sabemos e tendemos a desprezar ou tentar fazer desaparecer aquilo que nos desconforta em nosso desconhecimento.

A Modernidade inaugurou um tempo que Heidegger (filósofo alemão, 1889-1976) chamou de "Era da Técnica", em que é preciso conhecer para controlar e, desde então, assim temos vivido: entendendo que a racionalidade é o maior bem humano, a tecnologia um trunfo, a natureza um recurso e que todos os outros modos de ser só existem se avalizados pela razão.

No entanto, o sofrimento tem se mostrado mais pungente, a violência, em todas as suas formas, mais presente e os desastres mais catastróficos. É curioso, porque tudo isso nos pega de surpresa e até pouco tempo parecia-nos distante, fora de uma realidade que pudesse nos atingir diretamente. Agora, não mais. 
Vivemos um contexto difícil, de crise humanitária e de um modelo técnico-científico que norteou toda a modernidade. Temos assistido à destruição de ecossistemas e devastações ambientais; ao retorno de doenças consideradas erradicadas convivendo com novas doenças, ainda misteriosas e que causam danos irreversíveis; à hipermedicalização de emoções e sintomas na tentativa de enfrentar a vida; ao aumento de abusos e práticas violentas em todos os níveis.

Percebemos a emergência dos radicalismos, os desafios das mediações, das negociações e as dificuldades que temos tido de acessar aos outros nas experiências cotidianas e ordinárias. Nomeando-os, definindo-os e rotulando-os, a partir de imagens ou frases fora de contexto, enquadradas nas telas espertas dos smartphones. Estamos enquadrados, enquadrando... sem parar. E parece que nossos enquadramentos têm falhado, vide o aumento do número de suicídios, principalmente, entre jovens de 15 a 29 anos, fase de construção de identidade, projetos e esperança. Além do crescimento também significativo de licenças e afastamentos por depressão ou transtornos considerados vinculados à saúde mental no mundo do trabalho, lugar de realização de potenciais. A Organização Mundial da Saúde já havia declarado que, até 2020, a depressão seria a doença mais incapacitante do mundo. Essas constatações geram uma reflexão acerca de nossas práticas em psicologia, pois ao seguirmos tantos enquadres, não geramos espaço para vermos o novo, deixando escapar novas possibilidades mais fluídas.

\section{Ampliando o olhar}

"Nos deram espelhos e vimos um mundo doente." (Legião Urbana, 1986).

Impossível não nos remetermos à, absurdamente atual, obra Ensaio sobre a Cegueira (1995), onde Saramago nos convoca a ver e reparar, porque "só num mundo de cegos as coisas serão o que verdadeiramente são." (Saramago, 1995, p. 128).

Arthur Nestrovski, na orelha do livro de Saramago, nos chama a atenção para o romance onde "uma multidão de cegos precisará aprender a viver de novo" e onde a humanidade será reduzida "às necessidades e afetos mais básicos, um progressivo obscurecimento e correspondente iluminação das qualidades e dos terrores dos homens. ( $E$ das mulheres também, de maneira especial)." (Nestrovski, 1995).

$\mathrm{Na}$ epígrafe com a qual Saramago (1995) inaugura o romance, ele nos diz citando o Livro dos Conselhos: "Se podes olhar, vê. Se podes ver, repara". 
Com esta pequena frase que sintetiza quase toda a história, Saramago convida o leitor a percorrer um caminho onde não basta apenas "reparar no significado das coisas" (ou seja, adquirir o conhecimento sobre elas), "mas também de proceder à reparação do que foi perdido, ou mutilado." (Nestrovski, 1995). Nesses preciosos fragmentos literários, encontramos aliados que nos fazem refletir acerca de como nosso olhar encontra-se turvo, embaçado, nos impedindo um exercício mais livre de ver e poder reparar, apreciar e admirar-se.

Que cuidado então será necessário? Cabe aqui recuperar alguns significados da palavra, como atenção, cautela, precaução, solicitude, diligência, desvelo, encargo e inquietação. ${ }^{1}$

Se o cuidado é uma atitude possível, que seja primeiro atenção e inquietação diante do mistério e daquilo que não sabemos.

Ainda sobre um certo tipo de conhecimento, Pompéia nos diz acreditar que:

Nós, homens ocidentais, estamos todos em constante fuga diante do Caos . . . o grande inimigo a ser vencido pelo Conhecimento. O nosso conhecimento torna-se assim uma grande cruzada contra a gratuidade do acontecer das coisas.

Empenhados nesta cruzada contra a obscuridade da gratuidade nos agarramos à clareza da razão e, sem nos darmos conta, começamos a desejar - até desesperadamente - que o acontecer do mundo venha depender exclusivamente da nossa atuação fundada na clareza do já conhecido. (Pompéia, 1982, p. 39).

Isso nos põe diante da necessidade de controle e domínio. Deixamos de confiar no devir e tornamo-nos reféns de um tipo de racionalidade, que ambiciona o poder. Poder aqui "entendido como pura dominação da alteridade, seja ela representada pela outra pessoa, pela doença, pela sociedade ou pela conduta." (Pompéia, 1982, p. 42). Neste sentido, perpetuamos a cultura do mesmo, do igual e único modo de ser possível, aquele que, por nos parecer conhecido, torna-se, aos nossos olhos, previsível e passível de asseguramento e controle.

Contudo, "envolvidos que somos nestas questões, nos debatemos à procura de uma conduta profissional que possa ser mais do que mero arbítrio e exercício cego da dominação." (Pompéia, 1982, p. 42).

De novo: "Se podes olhar, vê. Se podes ver, repara." Que cuidado será possível?

Bauman, em um texto intitulado Como escapar da crise, nos diz que:

Há poucas chances de se sarar a doença sem a cooperação voluntária e dedicada, muitas vezes árdua e envolvendo sacrifício espontâneo do paciente. Todos nós somos pacientes 
no que diz respeito à doença sociocultural que nos afeta. Portanto há necessidade de cooperação de todos e de cada um. (Bauman, 2011, p. 164).

Parece que não há mais como fugir a essa responsabilidade. 0 cuidado se torna caminho acompanhado, como seguir de mãos dadas.

\title{
Abordagem gestáltica no fluxo do cuidado
}

A Gestalt-Terapia, desde o seu nascimento, vem trilhando um caminho que busca não se deixar enquadrar facilmente. Rebelde em sua origem, conserva a resistência necessária para não ceder às tentações aprisionantes de tais ou quais posições definidoras e definitivas de algum status quo.

Dialogando com a ciência, com a arte, com a espiritualidade e com diversos outros saberes e modos de ver o mundo, a Gestalt-Terapia não se confunde com eles em exclusividade, porque não ambiciona garantias. Preserva em sua essência a curiosidade viva do aqui e agora da experiência, do muitas vezes inexplicável vivido, cheio de significados, símbolos, sentimentos e sensações.

Valorizamos as vivências pessoais pré-reflexivas e refletidas nos encontros, e trabalhamos numa abordagem calcada no cotidiano, na cotidianidade das experiências, numa fenomenologia que inverte a lógica científica moderna tradicional e planta suas árvores no solo do cotidiano humano, fazendo da relação sujeito-objeto uma implicação (Josgrilberg, 2004).

Primeiro há uma implicação, e esta palavra traz em si o significado de envolvimento e não-neutralidade.

A teorização vem a posteriori, na tentativa de dizer da experiência e de compreendê-la. Antes não sabemos nada ou quase nada; talvez um pouco, pouco de nós mesmos...

Isso nos permite a abertura ao acontecer.

\author{
"A onda \\ a onda anda \\ aonde anda \\ a onda? \\ a onda ainda \\ ainda onda \\ ainda anda \\ aonde? \\ aonde? \\ a onda a onda." \\ (Bandeira, 2012, p. 286).
}


Assim como no poema de Manuel Bandeira, estamos também ao sabor deste fluxo incessante de movimento que a vida promove em nossa experiência. A força da Gestalt-Terapia está no propósito de nos mantermos atentos, aqui e agora, à onda do presente - 'aonde anda a onda?'

Neste mundo/mar não estamos sozinhos, pois já estamos imersos nele: ser-no-mundolser-no-mar. Somos seres sempre em relação, presentes neste sítio\lugar da existência - 'a onda anda, aonde anda a onda?'

Nosso trabalho se dá no encontro com outra pessoa. Esta que nos procura também chega com seu mundo/mar, com suas circunstâncias e ondas de vida. Este encontro promove, na aproximação destes mundos, a explicitação da alteridade, dimensão existencial e campo por onde seguimos em busca da criação de um possível nós.

O encontro destes mundos não favorece de pronto as condições necessárias para que a confiança propicie o surgimento do nós. A princípio, nem eu, nem o outro sabemos se será viável a criação de um caminho que nos leve a algum resultado comum. Possuímos ainda posições distintas, separadas pelos propósitos de cada um, e isso é, claro, perceptível, nítido pela indigência que o estar-no-mundo nos confere.

Quem é você? Nos perguntamos intimamente. A alteridade possibilita o saber de mim através do outro, é ele que me dá de volta. Sabemos de nós através do outro, mutuamente, mas não intencionalmente. Há nisso uma gratuidade inescapável; não há conhecimento prévio que nos salve disso.

A gratuidade da situação é soberana. É preciso aceitação e confiança no caminho do encontro com o outro; só assim será possível responder ao chamado que ele nos faz, pois desta forma, atualizamos a nossa presença comum. Neste sentido, esta é uma criação de possibilidade de autoconhecimento, nos atualizamos mutuamente através do 'espelhamento' que a alteridade nos possibilita. Passo a passo descobrimos condições para a criação de um fio com o qual será possível co-fiar/tecer o tecido da nossa confiança e, assim, o nós possa graciosamente ser conhecido.

Estar com o outro, menos munido de pressupostos teóricos, favorece um acompanhamento mais ingênuo, uma atitude menos reflexiva, mais contemplativa: olho vendo e escuto ouvindo - tempo gerúndio, presente.

Se necessário, vejo mais do que ouço ou ouço mais do que vejo - 'A onda anda, aonde anda a onda?' O necessário é o que se impõe, emerge, fica pregnante tanto pelo excesso quanto pela falta.

Serge e Anne Ginger, em seu livro Gestalt - Uma Terapia de Contato (1995), nos falam sobre a relativa objetividade quando nos recordam que "todo o mar sobe, com uma pedra que se lhe atire" (Ginger \& 
Ginger, 1995, p. 42) e nos convidam a uma leitura plural da realidade, dada à sua riqueza e condição multidimensional.

Às vezes, o olhar apura a audição, o que implica dizer que ouço também através dos olhos, naturalmente, organismicamente. "Diante da experiência, o organismo reage como totalidade organizada: não são os meus olhos que veem, sou eu que vejo." (Rudio, 1977, p. 24). Sou parte do todo e meu olhar interfere e confere sentido, sendo cocriador daquilo que vejo.

Dessa forma, uma atitude pré-reflexiva, como já mencionado, favorece um horizonte perceptivo mais amplo, que me inclui como parte do processo. Neste caso, a alteridade favorece a 'comunicação entre as experiências' e confirma a intersubjetividade. É importante lembrar que esta 'comunicação' não é deliberada, voluntária, mas sim uma função fenomenológica que se dá no campo relacional.

A alteridade esclarece diferenças (polos) e, nela, nos surpreendemos com a paridade possível, nos autoconhecemos atualizados no 'terreno do entre'. A intersubjetividade, se reconhecida, favorece, além da 'conversa íntima' entre as consciências/experiências, o possível e fortuito diálogo.

Este não é um acontecimento de longa duração. Nele, nos encontramos como ilhados (continência/terreno comum) pela indigência da gratuidade e da objetividade. Aqui, as palavras, agora, tornam-se veículos que favorecem o retorno ao ponto de partida, a resposta transformada em texto/contexto comum. Já podemos tratar do que é preciso. Mas, logo, ao mar voltaremos.
A concha
Ouço com espanto
teu canto marítimo,
trazes em teu pequeno bojo
todo o oceano. Como será possível?
Este é teu segredo e teu enigma e, se tento decifrá-lo, abrindo, perco-te.
Mas se te acolho em fina sintonia, transbordas em generosa entrega as tuas marés de vida. (Myra, 1998). ${ }^{2}$

Propondo uma epistemologia que tem como ponto de partida a experiência do observador/conhecedor, Maturana e Verden-Zoller (2004) há algum tempo já nos diziam que é preciso tocar o outro, tocar sem mediação de formas, receitas, técnicas prescritas, desde o início o corpo com corpo... corpo da mãe no corpo do bebê e viceversa... encontro onde se pode sentir o que o outro sente, quer, deseja, precisa. É a "biologia do amor", onde a continuidade da relação amorosa é "fundamental para o desenvolvimento fisiológico, 
para o desenvolvimento do corpo, das capacidades sensoriais, da consciência individual e social da criança." (Maturana \& VerdenZoller, 2004, p. 237).

"Confiança e aceitação num encontro corporal íntimo" (Maturana \& Verden-Zoller, 2004, p. 45) estão na base do conhecimento humano, da biologia do conhecer ou teoria da autopoiese, enunciada na contramão de uma ciência cognitiva explicativa, que conceitua e define sem considerar o sentir.

Um exemplo claro, desse aprisionamento moderno ocidental, pode ser observado no contexto materno-infantil atual, berço de nossos sistemas relacionais. Diante de tantas prescrições, em meio à avassaladora quantidade de informações externas, muitas mães já não acreditam em seu saber físico, orgânico, emocional e organísmico! É preciso o saber médico, científico, para autorizá-las em suas dificuldades de contato com seus corpos e consigo próprias.

\section{O contato como descoberta: como abrir os olhos e ver?}

A criança nos ensina! No jogo de tarot, o arquétipo do louco é a pura abertura, o número zero; na atitude filosófica, a admiração ingênua, a surpresa, a pura possibilidade; em Nietzsche, a derradeira transformação: o sim para o jogo da criação! "Inocência é a criança, e esquecimento; um novo começo, um jogo, uma roda a girar por si mesma, um primeiro movimento, um sagrado dizer-sim." (Nietzsche, 2006, p. 35).

A criança nos traz a primazia da experiência, da pré-reflexão, da natureza mesma da vida. Os nomes vêm depois, os porquês vêm depois e ainda assim vêm da curiosidade, da vontade, da alegria da descoberta. "Aprender é descobrir", já dizia Fritz Perls (1973), pai da Gestalt-Terapia.

O contato é inerente à descoberta. É preciso olhar, cheirar, tocar, colocar na boca algo que se quer conhecer. A criança faz contato e experimenta o tempo todo. E, assim, inaugura e ativa milhares de conexões neurais coloridas e brilhantes. O mundo é colorido!

A Gestalt-Terapia também nos resgata a importância e necessidade da experiência para as descobertas, em vários sentidos. E nos convoca ao olhar da abertura, do não já-visto, pensado, conhecido; das possibilidades, das revelações, do que é original!

Para isso, a Gestalt-Terapia nos convida a experimentar a experiência como o próprio experimento! Frente a frente, cara a cara, corpo a corpo. O mais livre possível de mediações conceituais e técnicas, confiantes na vivência i-mediata. Confiantes no processo costurado pelo fio relacional, este sim nosso maior bem, um fio de ouro, capaz de resistir a longos caminhos e percalços. 
Continuamos precisando repensar o lugar de nossas tecnologias terapêuticas. A que e a quem servem? Para que tantos coelhos na cartola? Muitas vezes não escondem o medo do encontro com o outro e seus mistérios, com as surpresas da vida, com o imprevisto, com o improvável e o imponderável? Afinal qual o lugar da criação?

". . o mais fundamental da postura fenomenológica jamais se reduz aos procedimentos metodológicos ou técnicos dela derivados, ou a seus resultados, mas à possibilidade de uma realização própria daquela atitude de disponibilidade à misteriosa alteridade . . ." (Souza, Leal, \& Sá, 2010, p. 228).

Estamos realmente dispostos? Num tempo onde "o dilema do desempenho do Eu e, consequentemente, o esvaziamento da intersubjetividade estão na base do sofrimento do homem" (Giovanetti \& Cardoso, 2019, p. 64), temos interesse e disponibilidade de ir ao encontro de um outro desconhecido e, exclusivamente na relação, construirmos caminhos, caminhos silvestres, selvagens?

O que queremos resgatar aqui é essa capacidade de confiar na beleza dos encontros como fonte de aprendizado, experiência e conhecimento. Não porque as palavras soem harmônicas, mas porque queremos ser coerentes nas atitudes tanto quanto parecemos ser nas palavras. Para tanto, precisamos agir com humildade; humildade intelectual e epistêmica (Schwartz \& Durrive, 2007).

Humildade por não sabermos o que ou quem é o outro, por considerarmos o mistério e a pluralidade de modos de existir, por acreditarmos na potência viva dos organismos e em suas infinitas e complexas relações, jamais completamente apreensíveis em teorias e conceitos formais. Também por acreditarmos na capacidade da vida de se reinventar, se recriar, se regenerar, surpreendendo, superando e transbordando modelos, protocolos e diagnósticos.

Gestalt terapeutas, terapeutas fenomenológico-existenciais, são antropólogos porque decidiram e praticam dedicar-se a ser parceiros, efetivos e imediatos, das pessoas, nos processos de suas invenções vivenciais e experimentais de si, nos momentos críticos de suas atualizações existenciais. Parceiros de pessoas, frequentemente em dificuldades, no contínuo processo da invenção de sua humanidade e da humanização de seus mundos. Em particular nos privilegiamos dos momentos de suas crises, do sofrimento, da vivência de seus limites e da superação deles. (Fonseca, 2005, p. 11).

No experimentar do fluxo terapêutico, o maior e mais belo experimento é a qualidade da relação criada, cultivada e aprimorada, com delicadeza e cuidado, entre terapeuta e cliente. 
Uma relação de verdade, construída no respeito aos acordos, aprendida nas tentativas bem e malsucedidas de tocar o outro e traduzir seus limites, encontrar seus espaços férteis e acreditar neles, cada um de um jeito próprio, singular e inédito. Ir sem saber, sabendo. Aprendendo sempre, aprendendo, aprendendo, aprendendo sempre.

A beleza do ofício é tecer o fio dourado que vincula, fortalece e faz acreditar na força do desconhecido:

- Posso dizer tudo? - Pode. - Você compreenderia? Compreenderia. Eu sei de muito pouco. Mas tenho a meu favor tudo o que não sei - por ser um campo virgem - está livre de preconceitos. Tudo o que não sei é a minha parte maior e melhor: é a minha largueza. É com ela que eu compreenderia tudo. Tudo o que não sei é que constitui a minha verdade. (Lispector, 1999, p. 415).

\section{Finalizando...}

Vivida na intimidade das relações e processos terapêuticos, a GestaltTerapia nos oferece um olhar próprio, sensível e abrangente, para o mundo da vida. Capaz de dialogar e dizer sim ao novo e ao diferente, acredita e estimula potencialidades, ajustamentos criativos, conhecimentos diversos, práticos e teóricos, na vontade de descobrir e compreender o outro.

Traduz-se, assim, como uma atitude que, "em sua essência, diz respeito ao cuidado propriamente dito, ou seja, à existência do outro e não a uma coisa de que se ocupa, ajuda o outro a tornar-se, em seu cuidado, transparente a si mesmo e livre para ele." (Heidegger, 1927 como citado em Sá, 2017, p. 58).

Neste sentido, a Gestalt-Terapia revela uma ética possível, como um lugar:

- De cuidado e esperança;

- De disponibilidade de seguir junto;

- De olho no olho;

- De relação de diálogo e confiança;

- De compreensão mais do que explicação;

- De presença;

- De acolhimento de tristeza e dor, mas também de alívio, alegria e humor;

- De inventividade e criação na força do aqui e agora; e

- De aceitação da morte, mas de afirmação da vida!

Em tempos de "fim de mundo", precisamos "suspender o céu" e respirar, ampliando nosso horizonte existencial (Krenak, 2019). 
Precisamos de outros saberes, sabores, vivências, redes de trocas e compartilhamentos, aprendizados solidários, generosidades.

Para isso, confirmamos a atualidade e potência dessa abordagem, nascida e criada na modernidade, mas com um olhar artístico, livre para ver, enxergar e agir no mundo, com coragem para uma certa ignorância, para o manancial de possibilidades e para toda a sabedoria viva que nos vier encontrar.

\section{Referências}

Bandeira, M. (2012). A estrela da tarde. São Paulo, SP: Global Editora.

Bauman, Z. (2011). 44 Cartas do Mundo Líquido Moderno. Rio de Janeiro, RJ: Zahar Editores.

Fonseca, A. H. L. (2005). Ensaios em Gestalt Terapia. Maceió, AL: Editora Pedang.

Ginger, S., \& Ginger, A. (1995). Gestalt - Uma Terapia do Contato. São Paulo, SP: Summus.

Giovanetti, J. P., \& Cardoso, C. L. (2019). Sofrimento Humano e Cuidado Terapêutico. Belo Horizonte, MG: Artesã Editora.

Josgrilberg, R. S. (2004). A fenomenologia como novo paradigma de uma ciência do existir. In D. D. Pokladek (Org.), $A$ fenomenologia do cuidar: prática dos horizontes vividos nas áreas da saúde, educacional e organizacional (pp. 31-52). São Paulo, SP: Vetor.

Krenak, A. (2019). Ideias para Adiar o Fim do Mundo. São Paulo, SP: Companhia das Letras.

Legião Urbana. (1986). Índios. Dois. Brasília: EMI.

Lispector, C. (1999). A Descoberta do Mundo. Rio de Janeiro, RJ: Rocco.

Maturana, H., \& Verden-Zoller, G. (2004). Amar e Brincar. Fundamentos Esquecidos do Humano. São Paulo, SP: Palas Athena.

Nestrovski, A. (1995). Em Saramago, J. (1995). Ensaio sobre a Cegueira (Orelha). São Paulo, SP: Companhia das Letras.

Nietzsche, F. (2006). Assim Falava Zaratustra. Rio de Janeiro, RJ: Ediouro.

Perls, F. (1973). A abordagem gestáltica e testemunha ocular da terapia. Rio de Janeiro, RJ: Zahar Editores.

Pompéia, J. A. (1982). A Análise Existencial: Alguns Fundamentos. In I. Porchat (Org.), As Psicoterapias Hoje (pp. 37-47). São Paulo, SP: Summus.

Rudio, F. V. (1977). Orientação não-diretiva na Educação, no Aconselhamento e na Psicoterapia. Petrópolis, RJ: Editora Vozes. 
Sá, R. N. (2017). Para Além da Técnica: Ensaios Fenomenológicos Sobre Psicoterapia, Atenção e Cuidado. Rio de Janeiro, RJ: Via Verita.

Saramago, J. (1995). Ensaio sobre a Cegueira. São Paulo, SP: Companhia das Letras.

Schwartz, Y., \& Durrive, L. (2007). Trabalho e Ergologia. Conversas sobre a atividade humana. Niterói, RJ: EdUFF.

Souza, L. R. A., Leal, I. F. A., \& Sá, R. N. (2010). Atitude fenomenológica e psicoterapia. Revista IGT na rede, 7(13), 223-245.

Recuperado

de https://www.igt.psc.br/ojs2/index.php/igtnarede/article/viewFil e/1967/2678

\section{Endereço para correspondência}

\section{Luciana Bicalho Cavanellas}

Rua Cesário Alvim 55, apto 904, BI. B, Humaitá, CEP 22261-030, Rio de Janeiro RJ, Brasil

Endereço eletrônico: lucianabcavanellas@gmail.com

\section{Ronaldo Miranda Barbosa}

Rua Madre Paula 165, apto 44, Vila Ema, CEP 12243-010, São José dos Campos SP, Brasil

Endereço eletrônico: barbosa.myra@gmail.com

Recebido em: 13/10/2019

Reformulado em: 06/02/2020

Aceito em: $10 / 02 / 2020$

\section{Notas}

* Psicóloga graduada pela UERJ em 1990, Mestre em Filosofia (UERJ /1998) e Doutora em Saúde Pública (Ensp/Fiocruz/ 2014). Gestalt Terapeuta desde 1991.

** Psicólogo clínico, especialização na Abordagem Gestáltica pelo Instituto Sedes Sapientiae (1984). Membro colaborador no Instituto Gestalt de São Paulo.

${ }^{1}$ Os significados da palavra cuidado foram consultados através do site Infopédia Dicionários Porto Editora. Recuperado de https://www.infopedia.pt/dicionarios/lingua-portuguesa/cuidado

${ }^{2}$ A poesia "A concha", escrita em 1998 por Myra, não foi publicada.

Este artigo de revista Estudos e Pesquisas em Psicologia é licenciado sob uma Licença Creative Commons Atribuição-Não Comercial 3.0 Não Adaptada. 